\title{
Empirical Relationships between Aftershock Zone Dimensions and Moment Magnitudes for Plate Boundary Earthquakes in Taiwan
}

\author{
by Wen-Nan Wu, Li Zhao, and Yih-Min Wu
}

\begin{abstract}
In this study, we establish the empirical relationships between the spatial dimensions of the aftershock zones and moment magnitudes $\left(M_{\mathrm{w}}\right)$ for the Taiwan region. The length $(l)$ and width $(w)$ of the aftershock zone of an earthquake is measured by the major and minor axes, respectively, of the ellipse of a two-dimensional Gaussian distribution of one-day aftershocks. Our data is composed of 649 mainshocks (depth $\left.\leq 70 \mathrm{~km}, M_{\mathrm{w}} 4.0-7.6\right)$ between 1990 and 2011. The relationships between aftershock zone dimensions and $M_{\mathrm{w}}$ were obtained by least-squares method with the corresponding uncertainties estimated by bootstrap. Our study confirms that aftershock zone dimensions are independent of faulting types and the seismic moment is proportional to $l^{3}$. The ratio $(w / l)$ increases slightly with $M_{\mathrm{w}}$ and is independent of faulting types. Together with previous study, our results suggest that earthquakes of both small $\left(M_{\mathrm{w}}=4.0\right)$ and large $\left(M_{\mathrm{w}} \geq 7.0\right)$ magnitudes have similar focal zone geometrical parameters. By using the $M_{\mathrm{w}}-S$ relation, where the aftershock zone area $S$ is estimated from $l$ and $w$, we also provide an independent examination of the variations in the median stress drop. We find that the median stress drops of strike-slip earthquakes are higher than those of thrust events. Moreover, the median stress drops are independent of the moment magnitudes for normal and strike-slip events but decrease for large thrust events. These results are consistent with the latest global observations. Regardless of faulting types, the median stress drop decreases for larger $\left(6 \leq M_{\mathrm{w}} \leq 7.6\right)$ and relatively deep (depth $\sim 60-70 \mathrm{~km}$ ) earthquakes.
\end{abstract}

Online Material: Effect of up-dip rupture propagation on estimated maximum slip duration, details on teleseismic and geodetic stations, and figures of far-field displacements, temporal change in slip, and snapshots of the semblance-value distribution.

\section{Introduction}

Over the past several decades, the empirical relationships between seismic moment $\left(M_{0}\right)$ or moment magnitude $\left(M_{\mathrm{w}}\right)$ and various earthquake faulting parameters (e.g., rupture length, width, and displacement) have been studied by a number of researchers on the basis of worldwide data sets (e.g., Scholz, 1982; Bonilla et al., 1984; Scholz et al., 1986; Romanowicz, 1992; Wells and Coppersmith, 1994; Pegler and Das, 1996; Wang and Ou, 1998; Mai and Beroza, 2000; Stock and Smith, 2000; Henry and Das, 2001; Hanks and Bakun, 2002, 2008; Kagan, 2002; Manighetti et al., 2007; Blaser et al., 2010; Leonard, 2010; Strasser et al., 2010) and regional data (e.g., Dowrick and Rhoades, 2004; Konstantinoua et al., 2005; Murotani et al., 2008; Yen and Ma, 2011). These scaling relationships provide not only useful empirical relationships for practical seismic hazard analyses but also perspective on earthquake physics (Shaw, 2009). An ongoing debate on whether the physical processes of earthquakes are independent of moment mag- nitudes and/or faulting types has risen from these observations. A number of global and regional studies have suggested that the rupture dimensions (rupture length, width, and area) are independent of moment magnitudes and/or faulting types (e.g., Wells and Coppersmith, 1994; Wang and Ou, 1998; Hanks and Bakun, 2002, 2008; Kagan, 2002; Dowrick and Rhoades, 2004), indicating that we can extrapolate from measurements of much more numerous smaller earthquakes to those of the rare and devastating greater events (Shaw, 2009). Several studies, however, have drawn opposite conclusions (e.g., Bonilla et al., 1984; Vakov, 1996; Mai and Beroza, 2000; Stock and Smith, 2000; Hanks and Bakun, 2002, 2008; Manighetti et al., 2007; Blaser et al., 2010; Leonard, 2010). For example, Mai and Beroza (2000) observed that the scaling relation is self-similar for dip-slip events but not for large strike-slip events. Multiple magnitude-length scaling relations based on fault segmentations have also been proposed (Manighetti 
et al., 2007). Furthermore, a self-similar model in which the seismic moment is proportional to the cube of the fault length (l) $\left(M_{0} \sim l^{3}\right)$ has been suggested (e.g., Kanamori and Anderson, 1975; Wells and Coppersmith, 1994; Kagan, 2002). Specifically, because the depth extent of earthquake rupture is limited by the finite seismogenic thickness for great earthquakes, the seismic moment is proportional to the fault length $\left(M_{0} \sim l\right)$ (Romanowicz, 1992, 1994; Romanowicz and Ruff, 2002), or the square of the fault length $\left(M_{0} \sim l^{2}\right)$ (Scholz, 1982, 1994a,b; Scholz et al., 1986). Recently, Leonard (2010) proposed scaling relations between the moment magnitude and fault length of $M_{\mathrm{w}} \sim l^{3}$ and $M_{\mathrm{w}} \sim l^{2.5}$, respectively, for events smaller and larger than $M_{\mathrm{w}}=5$ on the basis of a compilation of global data sets. Yen and Ma (2011) suggested that the relations between the seismic moment and fault length are $M_{0} \sim l^{2}$ and $M_{0} \sim l^{3}$, respectively, for events smaller and larger than $M_{\mathrm{w}}=7$ based on slip models mostly from the Taiwan region.

(a)

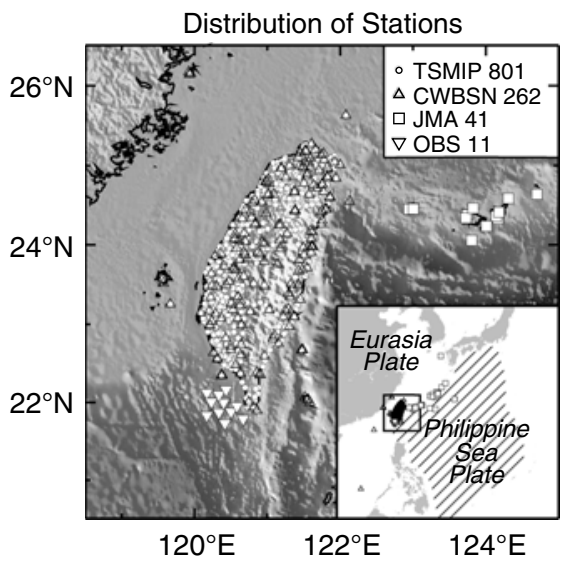

(b)

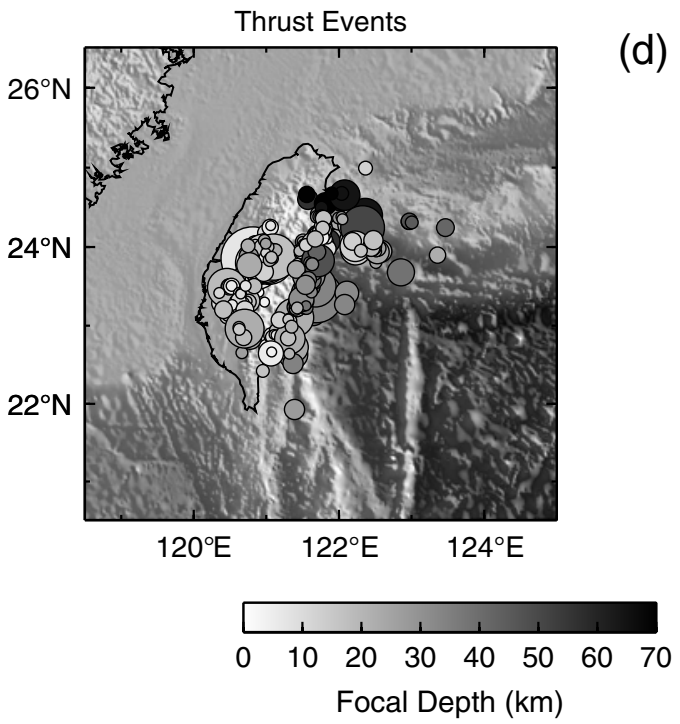

Taiwan is located along a strongly oblique convergent zone. To the northeast, the Philippine Sea Plate subducts northward beneath the Ryukyu Arc, where the Okinawa Trough, a back-arc basin, is developing, whereas in the south the Eurasia Plate subducts eastward beneath the Luzon Arc (Angelier, 1990; Sibuet et al., 1998; Hsu and Deffontaines, 2009; Fig. 1). This results in an active and complicated tectonic environment, including subduction, collision, and back-arc rifting. Earthquakes from small $\left(M_{\mathrm{w}} \sim 2\right)$ to large magnitude $\left(M_{\mathrm{w}}>6\right)$ with various faulting types (thrust, normal, and strike-slip focal mechanisms) occur frequently. To the best of our knowledge, however, the study of the empirical relations between focal zone geometrical parameters and magnitudes for earthquakes in Taiwan in particular has not received as much attention. Therefore, in this study we aim to establish a set of empirical relationships between aftershock zone dimensions and moment magnitude for the Taiwan region.

(c)
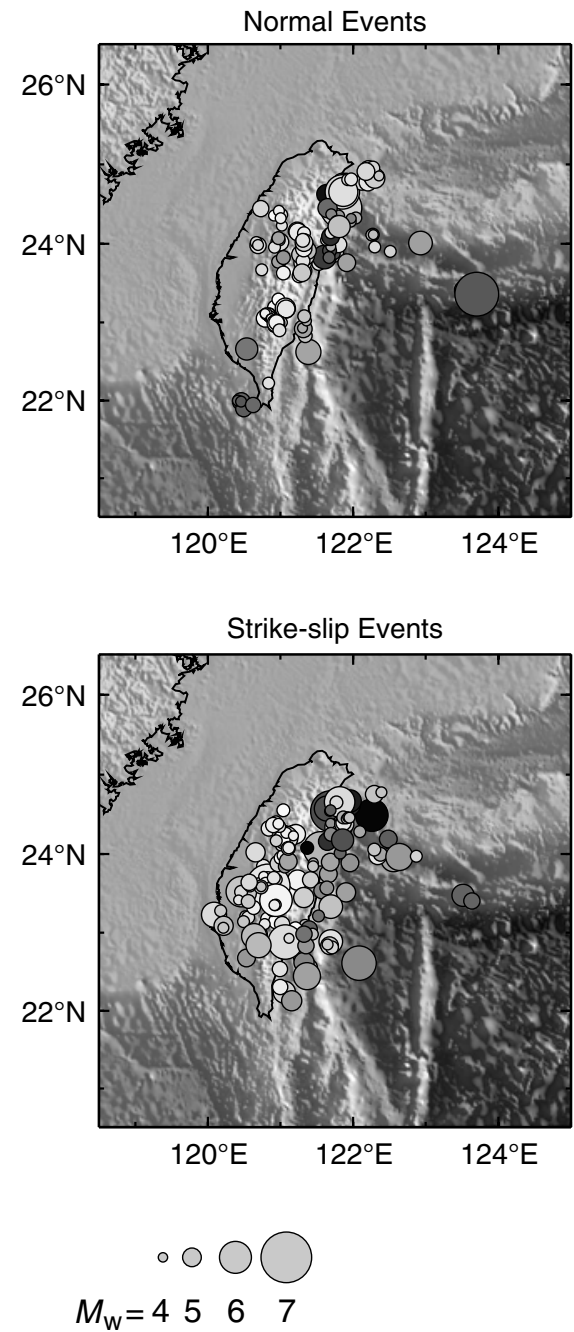

Figure 1. (a) Tectonic environment of Taiwan and seismic stations used in the relocation of earthquakes in Wu et al. (2009). (b-d) Distributions of shallow and relatively large (depth $\leq 70 \mathrm{~km}, M_{\mathrm{w}} \geq 4$ ) earthquakes with thrust, normal, and strike-slip faulting types, respectively. Mainshocks that meet the criteria for data selection and are used in scaling-relation regressions, circles. 
In establishing the empirical source scaling relations, a common way to estimate the earthquake rupture size is to rely on the distributions of either the coseismic slip (e.g., Somerville et al., 1999; Mai and Beroza, 2000; Murotani et al., 2008; Yen and Ma, 2011) or the aftershock locations (e.g., Wells and Coppersmith, 1994; Henry and Das, 2001; Kagan, 2002; Konstantinoua et al., 2005; Leonard, 2010; Strasser et al., 2010). The major drawbacks of these approaches, however, are that the solution in the coseismic slip inversion is often not unique (Beresnev, 2003; Zahradník and Gallovič, 2010), and the definition of the aftershock zone can be subjective (Tajima and Kanamori, 1985a,b; Kagan, 2002; Tajima and Kennett, 2012). These ambiguities introduce large uncertainties in delineating the rupture size and establishing the empirical source scalings. Although the aftershock mapping method has the weakness of subjective judgment, it allows for a lower moment magnitude threshold in the mainshocks selection and, therefore, enables us to use a greater number of events to derive empirical relationships. A large number of available events are favorable for the empirical relationship regression study, especially in the case where data are further divided to examine the dependence on the magnitudes and focal mechanisms of earthquakes as well as other earthquake source parameters. We, thus, adopt a quantitative technique to measure aftershock zone dimensions by aftershock distribution. It is well known, however, that the aftershock location quality and the numbers of aftershocks decrease with decreasing magnitude, which may make the estimation of aftershock zone dimensions less reliable. To solve the above dilemma, each mainshockaftershock sequence must have more than 10 events to have statistical significance, and the lower moment magnitude threshold in our mainshock selection is down to $M_{\mathrm{w}}=4$ by taking into account the uncertainty of hypocenter locations and the finiteness of earthquake sources.

Kagan (2002) has used a two-dimensional Gaussian distribution of the one-day aftershocks to quantify the spatial content of an aftershock zone and derive a global scaling for the aftershock zones of large shallow events (depth $\leq 70 \mathrm{~km}$, $\left.M_{\mathrm{w}} \geq 7.0\right)$. In this study, we begin by following the approach of Kagan (2002) to quantitatively estimate the aftershock zone sizes and establish the empirical relationships between the moment magnitude and the aftershock zone length, width, and area for the Taiwan region. Then we compare our results with those from the globally derived relationships. In particular, we are mostly interested in comparing our derived relationships with those proposed by Kagan (2002) to examine whether earthquake faulting parameters differ between large and small earthquakes of different faulting types. We, thus, analyze all events in a consistent manner with Kagan (2002). The lower moment magnitude threshold in the mainshock selection in Kagan (2002) is larger than $M_{\mathrm{w}} 7$. By contrast, in our data set most of the mainshocks range from $M_{\mathrm{w}} 4$ to $M_{\mathrm{w}} 7$; thus, our analysis is complementary to the aftershock zone scaling of Kagan (2002).
Furthermore, the stress drop $(\Delta \sigma)$, the difference between the average state of stress on the fault plane before and after an earthquake (Allmann and Shearer, 2007), is one of the most important earthquake source parameters. The issue of whether the stress drop is magnitude dependent or depth dependent is still open to debate (Allmann and Shearer, 2007, 2009; Hardebeck and Aron, 2009). There have been many efforts to resolve these controversies, mainly by improving the reliability and stability of the earthquake source spectra (e.g., Mayeda and Walter, 1996; Prieto et al., 2004; Allmann and Shearer, 2007, 2009; Mayeda et al., 2007). In this study, we relate the stress drop to our derived relations between the moment magnitude and aftershock zone area. Our approach is free from the limitation of using earthquake source spectra to retrieve the stress drop, and we can provide an independent examination of the scaling behavior for the stress drop.

\section{Data and Analysis}

\section{Earthquake Catalogs and Data Selection}

To derive the scaling relationships of aftershock zone dimensions with moment magnitude for the Taiwan region, a latest high-quality seismicity catalog between 1990 and 2011 is used. A comprehensive data set of the arrival times from the Taiwan Central Weather Bureau Seismic Network (CWBSN), Taiwan Strong Motion Instrumentation Program (TSMIP), Japan Meteorological Agency (JMA), and 11 one-week ocean bottom seismometers were used to relocate earthquakes by applying a 3DCOR program (Wu et al., 2003 ) to the latest three-dimensional velocity model ( Wu et al., 2007, 2009). The residuals of $P$-wave arrival times and $S-P$ times are largely reduced, and a total of 588,329 relocated earthquakes are available. The average horizontal and depth location errors within one standard deviation are $0.29 \pm 0.37$ and $0.32 \pm 0.47 \mathrm{~km}$, respectively. Furthermore, the average completeness magnitude of this earthquake cata$\log$ is $1.97 \pm 0.08$, which is estimated by using the maximum curvature method from Woessner and Wiemer (2005) and 200 bootstrap resamplings.

After relocation, first-motion focal mechanisms of 6249 earthquakes of magnitude $M_{\mathrm{L}}=1.5$ and above were determined by a nonlinear grid search based on the genetic algorithm (Wu, Zhao, et al., 2008; Wu et al., 2010). The resulting high-quality data set greatly reduces the uncertainties in the estimation of aftershock zone sizes and the ambiguity in the establishment of empirical relationships for different faulting types.

The local magnitude $M_{\mathrm{L}}$ is routinely estimated for all earthquakes recorded at the CWBSN. Here we convert the local magnitude $M_{\mathrm{L}}$ to moment magnitude $M_{\mathrm{w}}$ using the $M_{\mathrm{L}}-M_{\mathrm{w}}$ empirical relationship proposed by Chen et al. (2009)

$$
M_{\mathrm{L}}=0.8 M_{\mathrm{w}}+1.264 .
$$

After magnitude conversion, moderate and large shallow earthquakes (depth $\leq 70 \mathrm{~km}, M_{\mathrm{w}} \geq 4$ ) are then selected as 
potential candidates of the mainshocks from the CWBSN catalog, and their corresponding focal mechanism solutions are from the first-motion focal mechanism catalog. In total, there are 1038 potential mainshocks selected for further analysis.

To measure the aftershock zone dimensions of a mainshock, we select all the events within one day after the occurrence of the mainshock (e.g., Tajima and Kanamori, 1985a,b; Pegler and Das, 1996; Henry and Das, 2001; Kagan, 2002; Tajima and Kennett, 2012) that have hypocentral distances from the mainshock shorter than the maximum distance predicted by the magnitude-dependent relation proposed by Kagan (2002)

$$
R_{\mathrm{m}}=20 \times 10^{\left(M_{\mathrm{w}}-6\right) / 2} \mathrm{~km} .
$$

To avoid using earthquakes from other sequences, we only use the earthquake sequence in which the mainshock is the first event within the sequence and is at least one moment magnitude unit larger than the second largest earthquake (Bath, 1965). In addition, to ensure the statistical significance, each mainshock-aftershock sequence must have more than 10 events (Kagan, 2002).

As a result, there are a total of 649 groups of mainshockaftershock sequences (Fig. 1). Among them, 349 (53\%) are sequences with thrust-type mainshocks, 127 (20\%) with normal-fault mainshocks, and $173(27 \%)$ with strike-slip mainshocks. Such a large number of events in our final data set promises to reduce the uncertainties in source parameters and the estimation of aftershock zone dimensions.

\section{Parameters of Aftershock Zone Dimensions}

In this study, we obtain the spatial distribution parameters of aftershock sequences using the approach of Kagan (2002). Here, we briefly explain this method to facilitate our later discussion. In principle, an aftershock zone is a manifestation of a fault rupture in a three-dimensional volume. Nevertheless, as demonstrated by Kagan (2002), no significant difference is found between the aftershock zone dimensions approximated by a two-dimensional and a three-dimensional Gaussian distribution. For this reason, we approximate all the aftershock zones in our catalog by two-dimensional Gaussian distributions, the probability density contours (confidence area) of which are ellipses. The major axis, minor axis, and the area of the ellipse are used to measure the aftershock zone length, width, and area, respectively.

We first obtain the basic parameters for an aftershock sequence composed of $N$ events by calculating the sums

$$
\begin{gathered}
(x x)=\sum_{i=1}^{N}\left(x_{i}-\bar{x}\right)^{2}, \\
(y y)=\sum_{i=1}^{N}\left[\left(y_{i}-\bar{y}\right) \cos (\bar{x})\right]^{2},
\end{gathered}
$$

and

$$
(x y)=\sum_{i=1}^{N}\left(x_{i}-\bar{x}\right)\left(y_{i}-\bar{y}\right) \cos (\bar{x})
$$

where $x_{i}$ and $y_{i}$ are the latitude and longitude, respectively, of $i$ th aftershock, and $\bar{x}$ and $\bar{y}$ are the average latitude and longitude, respectively, of all events in the sequence.

Then, the correlation coefficient $\rho_{\mathrm{a}}$ and the major $\left(\sigma_{\mathrm{j}}\right)$ and minor $\left(\sigma_{\mathrm{n}}\right)$ semi-axes of the ellipse are defined as

$$
\begin{gathered}
\rho_{a}=\sqrt{\frac{(x y)}{(x x)(y y)}}, \\
\sigma_{j}^{2}=\frac{1}{2(N-1)}[(x x)+(y y) \\
+\sqrt{\left.[(x x)-(y y)]^{2}+4 \rho_{a}(x x)(y y)\right]}, \\
\sigma_{n}^{2}=\frac{1}{2(N-1)}[(x x)+(y y) \\
-\sqrt{\left.[(x x)-(y y)]^{2}+4 \rho_{a}(x x)(y y)\right]} .
\end{gathered}
$$

The length $(l)$ and width $(w)$ of an aftershock zone are defined as the length and width of the $2 \sigma$ confidence area, respectively,

$$
\begin{gathered}
l=4 \sigma_{\mathrm{j}}, \\
w=4 \sigma_{\mathrm{n}} .
\end{gathered}
$$

Note that here the aftershock zone length $(l)$ and aftershock width $(w)$ represent the maximum and minimum dimensions of the aftershock zone, respectively. Moreover, the aftershock zone width $(w)$ may not necessarily be related to the depth extent of mainshocks.

The decimal logarithms of $l$ and $w$ are denoted as

$$
\begin{gathered}
L=\log _{10} l, \\
W=\log _{10} w .
\end{gathered}
$$

The decimal logarithm of the aftershock zone area can be defined by the area of the ellipse as follows:

$$
A=\log _{10} s=\log _{10}\left(\pi \times \sigma_{\mathrm{j}} \times \sigma_{\mathrm{n}}\right) .
$$

Finally, we calculate the standard deviation $\left(\sigma_{\mathrm{a}}\right)$ of an aftershock zone by the equation

$$
\sigma_{a}^{2}=\frac{(x x)(y y)-(x y)^{2}}{n(x x)} .
$$

Figure 2 shows an aftershock area for an earthquake that occurred in southwestern Taiwan and the associated 


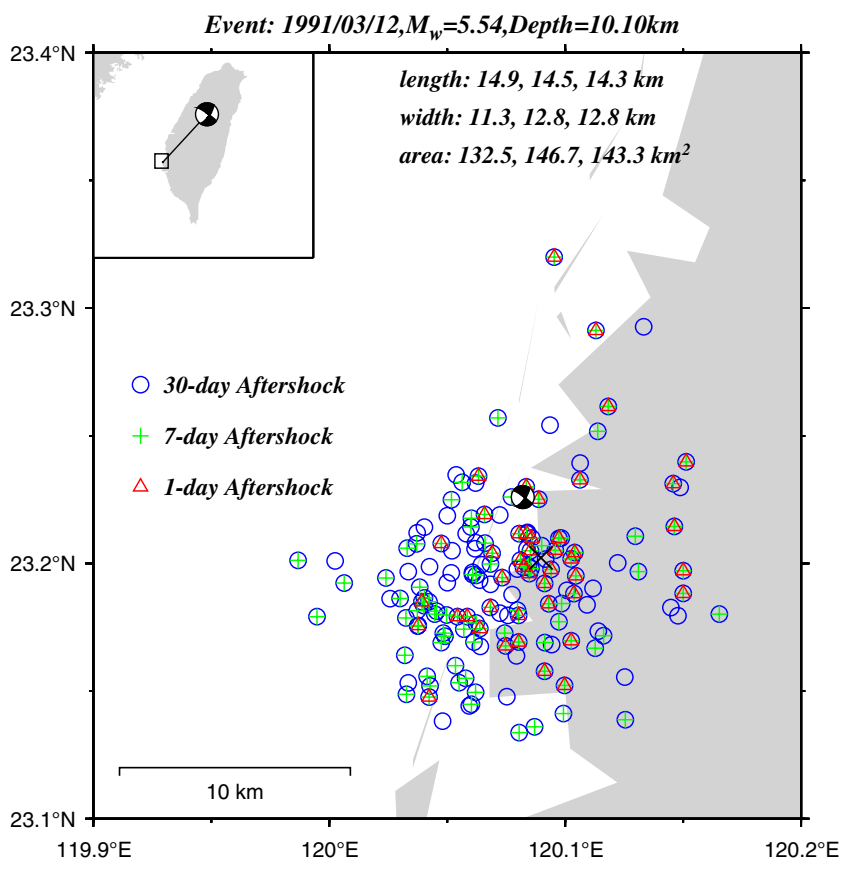

Figure 2. An example showing the distribution of aftershocks and the estimation of aftershock zone dimensions. Upper left inset shows the location and focal mechanism of the mainshock. The estimations for 1-day, 7-day, and 30-day sequences are, respectively, $14.9,14.5$, and $14.3 \mathrm{~km}$ for the aftershock zone length; 11.3 , 12.8 , and $12.8 \mathrm{~km}$ for the aftershock zone width; and 132.5, 146.7, and $143.3 \mathrm{~km}^{2}$ for the aftershock zone areas. The color version of this figure is available only in the electronic edition.

estimations of aftershock zone dimensions. For a complete list of earthquakes and their aftershock zone dimensions, see (E) Table S1 in the electronic supplement to this article.

\section{Regression Coefficient and Uncertainty}

The scaling relationships between the aftershock zone dimensions (length $l$, width $w$, and area $s$ ) and the moment magnitude $M_{\mathrm{w}}$ are expressed as

$$
\begin{gathered}
L=\log _{10}(l)=a_{L}+b_{L} M_{\mathrm{w}}, \\
W=\log _{10}(w)=a_{W}+b_{W} M_{\mathrm{w}}, \\
A=\log _{10}(s)=a_{A}+b_{A} M_{\mathrm{w}} .
\end{gathered}
$$

The regression coefficients in these scaling relations are determined by a weighted linear least-squares method with the standard deviation $\left(\sigma_{\mathrm{a}}\right)$ of each aftershock zone dimensions being taken into account (Press et al., 1992), which significantly reduces uncertainty.

Moreover, we use a bootstrap method to estimate the uncertainties of the regression coefficients. At every regression, we take a subset of the events from its entire population, allowing each event to be selected more than once. We repeat this procedure 5000 times and then compute the mean value and the one standard deviation (68\% confidence level) from these 5000 regressions. In this way, the mean estimation takes into account the uncertainties of the aftershock zone determinations, which ensures the stability and reliability of the estimations (e.g., Woessner and Wiemer, 2005). We also compute the linear cross-correlation coefficients (Pearson's coefficient, $r$; Press et al., 1992) between our data and the values predicted by our derived empirical relationships to measure the similarity between observations and predications.

\section{Results and Discussion}

\section{Aftershock Zone Scaling}

Figure 3 shows the best-fitting regression lines and their $68 \%$ confidence levels of the scaling relationships $L-M_{\mathrm{w}}$, $W-M_{\mathrm{w}}$, and $A-M_{\mathrm{w}}$ for all events together as well as for thrust, normal, and strike-slip events, separately. In our results, all the $L-M_{\mathrm{w}}, W-M_{\mathrm{w}}$, and $A-M_{\mathrm{w}}$ relationships have a very high correlation coefficient $(\geq 0.94)$, indicating a good self-consistency between the regression results and the observations. Thus, for every relationship between mainshock faulting parameter and moment magnitude, the bestfitting lines of regressions for various faulting types are identical within one standard deviation (Fig. 3). From this observation, we conclude that the scaling relationship is independent of faulting types, which is consistent with previous studies (Wells and Coppersmith, 1994; Kagan, 2002).

In addition, to examine the possibility of a breakdown in the scaling relations for the Taiwan region, we conduct the same regression analysis with respect to three magnitude bins $\left(4 \leq M_{\mathrm{w}}<5,5 \leq M_{\mathrm{w}}<6\right.$, and $\left.6 \leq M_{\mathrm{w}} \leq 7.6\right)$. The results show that the width of the slope range for moderate normal events $\left(5 \leq M_{\mathrm{w}} \leq 6\right)$ is relatively large compared to others (Fig. 4). We find that the number of these moderate normal events is relatively small (12 events), and they are evenly distributed from southern Longitudinal Valley to northeastern Taiwan representing the different local tectonics (Fig. 1c). We, therefore, infer that such a large variation in the slope of the best-fitting regression for moderate normal events may be related to the large difference in local tectonics. Despite the large uncertainty in the slope range for moderate normal events, no statistical difference in each separate calculation is found (Fig. 4). We, thus, conclude that these empirical relationships remain valid for all magnitudes (i.e., self-similarity) within our data set. Our results, however, may be specific for Taiwan and similar tectonics, and may not be applicable to the continental transform and extensional environments.

\section{Comparison with Previous Studies}

Kagan (2002) only provided the scaling relation between the moment magnitude and aftershock zone length, and this is compared with our result in Figure 3. For rupture width and area, however, we compare our regression results 
(a)
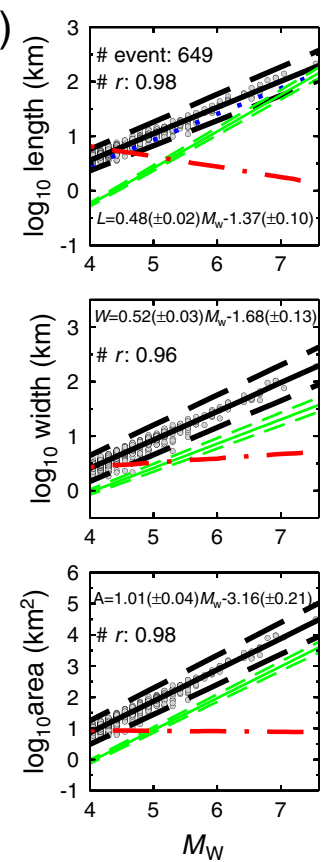

(b)

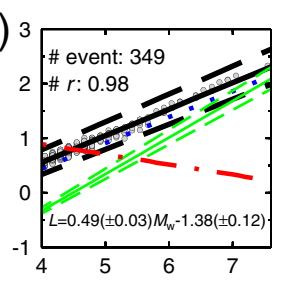

(c) 3

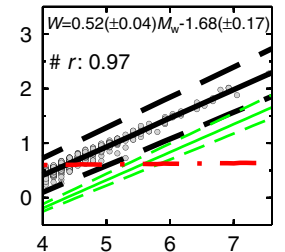

$6 \longdiv { 1 }$

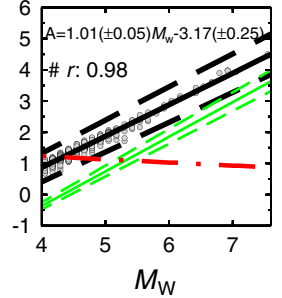

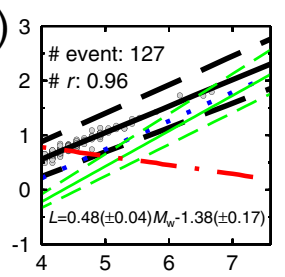

(d) 3
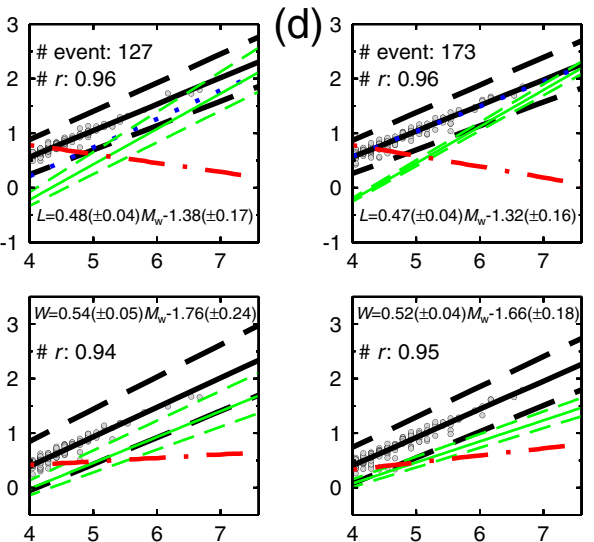

$3=0.52( \pm 0.04) M_{w}-1.66( \pm 0.18)$
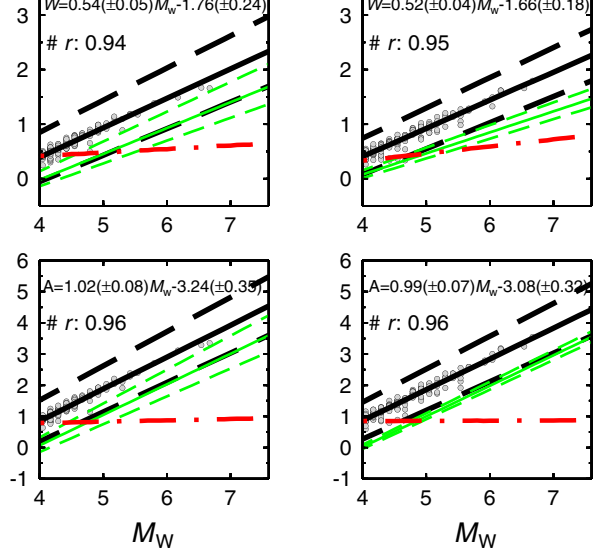

Figure 3. Diagrams showing the $L-M_{\mathrm{w}}, W-M_{\mathrm{w}}$, and $A-M_{\mathrm{w}}$ scaling relationships obtained from Taiwan earthquakes in our catalog. (a) All events, (b) thrust events, (c) normal events, and (d) strike-slip events. Thick solid lines represent the best-fitting lines to the data (circles), and the thick dashed lines are the 68\% confidence limits. Dotted lines are results of Kagan (2002). Thin solid lines represent the results of Wells and Coppersmith (1994), and the thin dashed lines are the 68\% confidence limits. Dot-dashed lines represent the residual between our results and these of Wells and Coppersmith (1994); $r$ stands for the correlation coefficient between observations and predictions by our regression relationships. The color version of this figure is available only in the electronic edition.

(a)
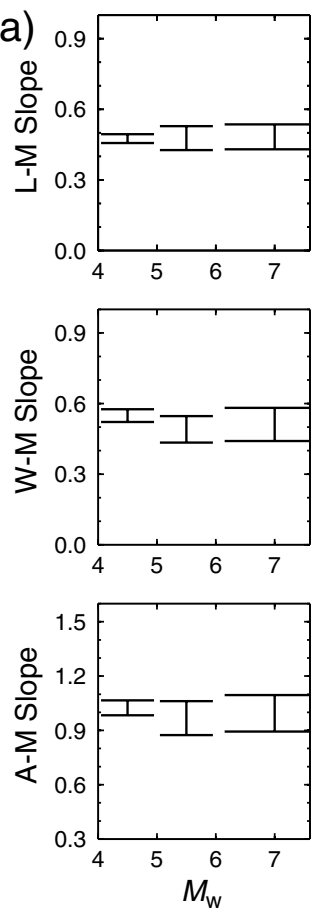

(b)
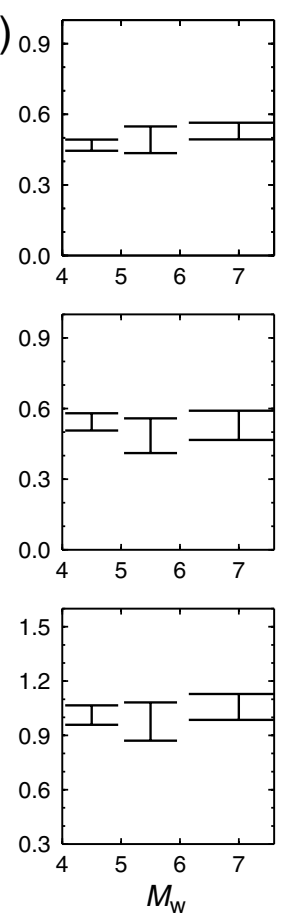

(c)
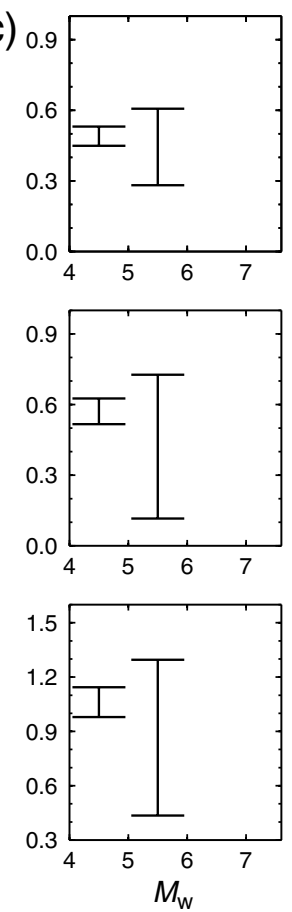
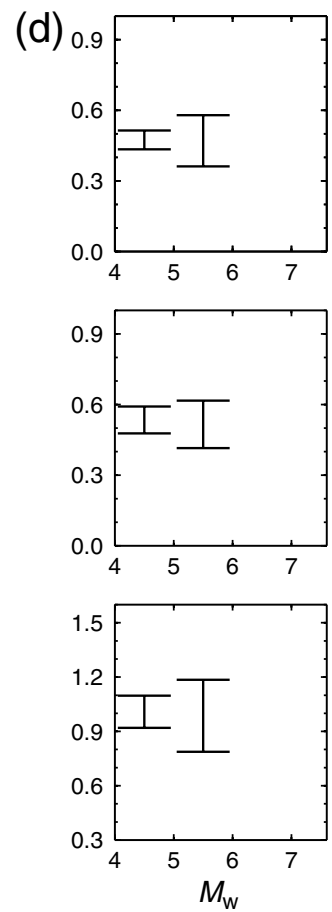

Figure 4. Diagrams showing the values of the slope in $L-M_{\mathrm{w}}, W-M_{\mathrm{w}}$, and $A-M_{\mathrm{w}}$ relationships for (a) all events, (b) thrust events, (c) normal events, and (d) strike-slip events. Error bar indicates the $68 \%$ confidence limits. 
with the widely used relationships proposed by Wells and Coppersmith (1994). We do not make any comparison between our relationships and those derived from coseismic slip models for the Taiwan region by Yen and Ma (2011), as they represent two different approaches in the estimation of fault geometry.

A comparison between our derived $L-M_{\mathrm{w}}$ relations with those of Kagan (2002) shows a good agreement for all events as well as for thrust and strike-slip events (Fig. 3a,b,d). In particular, the best-fitting line for strike-slip events by Kagan (2002) almost coincides with our regression result (Fig. 3d). Although there is less consistency for normal events (Fig. 3c), the agreement is still up to the $68 \%$ confidence level. We conclude that our derived $L-M_{\mathrm{w}}$ relations are consistent with those of Kagan (2002).

On the other hand, Figure 3 shows that the best regression lines of Wells and Coppersmith (1994) for $L-M_{\mathrm{w}}$ relations deviate from ours significantly for the events with $M_{\mathrm{w}}<6$. Moreover, the slopes of the best regression lines of Wells and Coppersmith (1994) for $W-M_{\mathrm{w}}$ and $A-M_{\mathrm{w}}$ relations are similar to ours, indicating that aftershock zone width and area derived from the two-dimensional Gaussian distribution are proportional to those from a subjective selection of aftershocks by Wells and Coppersmith (1994). The average differences between our estimations and those of Wells and Coppersmith (1994) are $23 \mathrm{~km}, 36 \mathrm{~km}$, and $3496 \mathrm{~km}^{2}$ for length, width, and area, respectively. Such large differences may be because the subsurface rupture length estimates in Wells and Coppersmith (1994) are subjective, the majority of their data come from large and shallow events $\left(M_{\mathrm{w}}>6\right.$, depth $\left.\leq 40 \mathrm{~km}\right)$, and the aftershock zone width we defined is the low-end (or minimum) estimation of the aftershock zone and may not be the same to the down-dip rupture width estimated by the depth distribution of aftershocks for the best-defined aftershock zone in Wells and Coppersmith (1994).

\section{Scaling Exponent of the $L-M_{\mathrm{w}}$ Relationship}

The moment magnitude $M_{\mathrm{w}}$ can be related to the seismic moment $M_{0}$ by the following equation (Hanks and Kanamori, 1979):

$$
M_{\mathrm{w}}=2 / 3 \log _{10} M_{0}-10.7 \text {. }
$$

We have also obtained the relationship between the magnitude moment $M_{\mathrm{w}}$ and the logarithm of aftershock zone length $(l)$ for all events

$$
L=\log _{10} l=0.48 M_{\mathrm{w}}-1.37 \text {. }
$$

Substituting equation (18) into equation (19) yields

$$
\begin{aligned}
\log _{10} l & =0.48\left(2 / 3 \log M_{0}-10.7\right)-1.37 \\
& =0.32 \log _{10} M_{0}-5.136 .
\end{aligned}
$$

Therefore, we obtain the scaling relation of seismic moment $M_{0}$ with the aftershock zone length $l$

$$
M_{0} \propto l^{3.125} .
$$

When taking the uncertainty of the regression coefficient into account, the value of the exponent in the $M_{0}-l$ scaling relation in equation (21) is $3.13 \pm 0.13$, which is in a good agreement with the $M \propto l^{3}$ model (Kanamori and Anderson, 1975; Kagan, 2002). Together with the observation of Kagan (2002), we suggest that the $M \propto l^{3}$ power scaling holds from small $\left(M_{\mathrm{w}}=4.0\right)$ to large $\left(M_{\mathrm{w}} \geq 7.0\right)$ events, reflecting the similarity in earthquake focal zone geometrical parameters.

\section{Aspect Ratio}

One assumption in the $M \propto l^{3}$ power-law model is that the aspect ratio $\left(w_{d} / l_{s}\right)$, where $l_{s}$ is the length of the best-defined aftershock zone along strike and $w_{d}$ is the down-dip fault width representing the depth extent of the mainshock (e.g., Kanamori and Anderson, 1975; Henry and Das, 2001; Blaser et al., 2010; Leonard, 2010), is constant (Kanamori and Anderson, 1975). The dependence of the aspect ratio on moment magnitude and faulting types, however, has been reported previously (Henry and Das, 2001; Blaser et al., 2010; Leonard, 2010). Here we also address the issue of whether the ratio of the aftershock zone width $(w)$ and aftershock zone length $(l)$ change with moment magnitude for different faulting types. Note that our estimated ratio $(w / l)$ is different from the conventional definition of the aspect ratio $\left(w_{d} / l_{s}\right)$. In other words, our estimated ratio of $(w / l)$ could be explained in terms of the ratio of the minimum dimension $(w)$ divided by the maximum dimension $(l)$ of the aftershock zone. Figure 5 shows that the ratio $(w / l)$ is independent of faulting types and increases slightly with $M_{\mathrm{w}}$. This shows that the minimum dimension grows faster than the maximum dimension with increasing moment magnitude.

\section{Stress Drop}

It is well known that the stress drop can be related to the moment magnitude $M_{\mathrm{w}}$ and fault area on the basis of a circular fault model (e.g., Hanks and Bakun, 2002)

$$
\log _{10} \Delta \sigma=1.5\left(M_{\mathrm{w}}-\log _{10} A+10.958\right),
$$

where $A$ is the rupture area $\left(\mathrm{cm}^{2}\right)$, and $\Delta \sigma$ is the stress drop $\left(\times 10^{7}\right.$ dyne $\left./ \mathrm{cm}^{2}\right)$.

According to the above equation, we compute the stress drop for the earthquakes in our catalog and examine their variations with respect to moment magnitude and depth for various faulting types. The merit of this method is to avoid the complications in computing the spectral corner frequency using seismic waveforms, such as a priori assumption of the source model, limitation in the frequency bandwidth, and the effect of medium attenuation (e.g., Mayeda and Walter, 
(a)

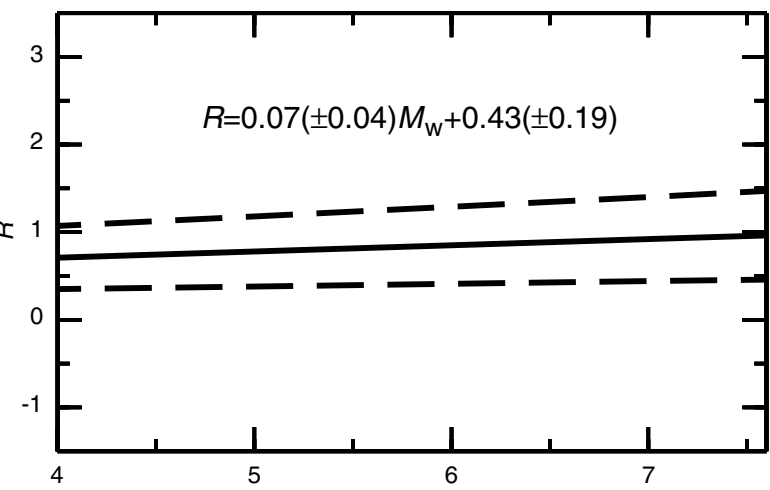

(b)

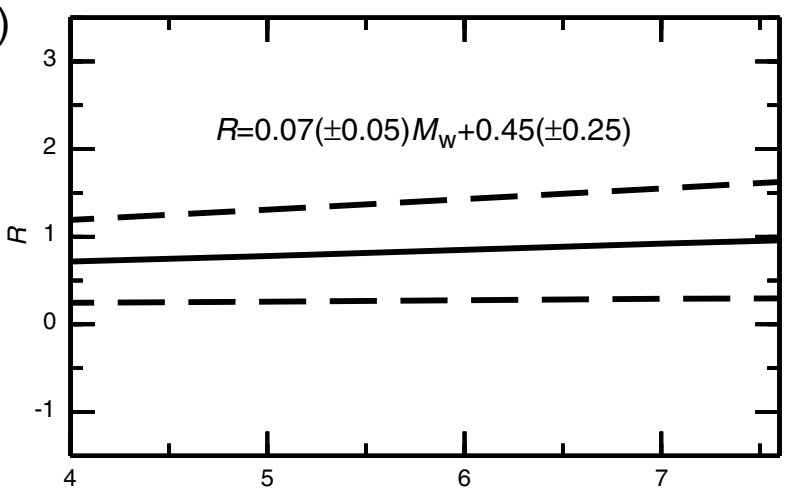

(c)

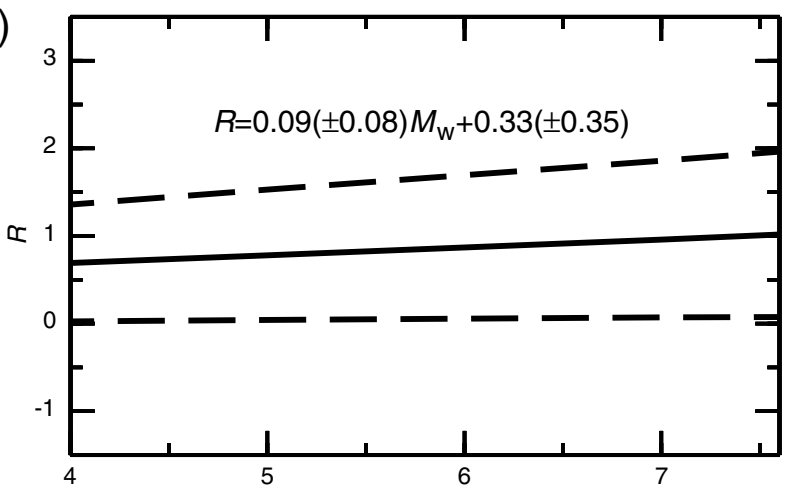

(d)

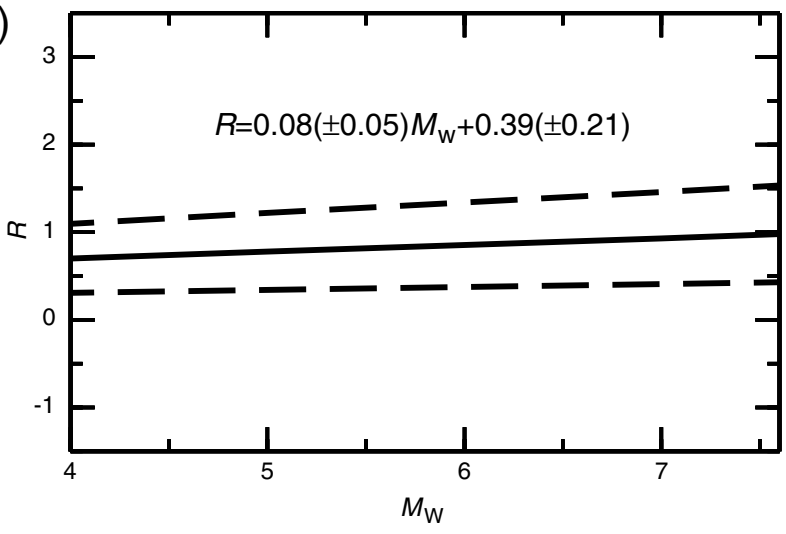

Figure 5. Diagrams of the ratio $R(w / l)$ versus moment magnitude for (a) all events, (b) thrust events, (c) normal events, and (d) strike-slip events. Solid lines represent the best-fitting lines to the data, and the dashed lines indicate the $68 \%$ confidence limits in our regression.
1996; Prieto et al., 2004; Allmann and Shearer, 2007, 2009; Mayeda et al., 2007; Hardebeck and Aron, 2009). The results show that the stress drop ranges from 0.06 to $0.84 \mathrm{MPa}$ with a median value of $0.15 \mathrm{MPa}$, which is considerably lower than the median stress drop in the latest global observation (4 MPa) (Allmann and Shearer, 2009). In addition, we find that the values of our derived stress drops are lower than those of Huang et al. (2002) and Chi and Dreger (2002) for the aftershocks of the Chi-Chi earthquake. We further compare our estimations of aftershock zone dimensions with those derived from waveform modeling of finite-fault models by Chi and Dreger (2004) for six $M_{\mathrm{w}}>5.8$ Chi-Chi aftershocks. A comparison shows that our estimations are several times larger than those by Chi and Dreger (2004). This may explain why our estimated stress drops are relatively smaller than those of Huang et al. (2002) and Chi and Dreger (2002). Additionally, the stress drop of the 25 September 1999, ChiChi aftershock $\left(M_{\mathrm{w}}=6.4\right)$ estimated by Huang et al. (2002; $99.1 \mathrm{MPa}$ ) is ten times larger than that of Chi and Dreger (2002; $9.9 \mathrm{MPa})$. This suggests that the estimation of the stress drop may vary with the different methods.

We realize that error exists in the conversion from $M_{\mathrm{L}}$ to $M_{\mathrm{w}}$ in equation (1), but our unusually low value of the stress drop seems mainly to have resulted from the relatively large aftershock zone area. Moreover, approximation of the aftershock zone area may not be the same as the true rupture area. Therefore, in this study we do not compute the deterministic values of the stress drop, and the values of the stress drop are meaningful only when considering their relative variations. If we conduct the same analysis using a more restrictive value of the level of the aftershock zone (i.e., $1 \sigma$ confidence area, (E) see Figs. S4 and S5 in the electronic supplement to this article), the stress-drop values increase by one order of magnitude, but their relative variation patterns are similar to those using a $2 \sigma$ confidence area. Therefore, in what follows we still base our discussion on the results obtained using a $2 \sigma$ confidence area.

We first compute the median stress drop for all events of different faulting types and test the robustness of the resulting median values by bootstrap method as stated in section of parameters of aftershock zone dimensions (Fig. 6a). A correlation of the stress drop with faulting types is expected based on the Anderson faulting theory (Anderson, 1951), which suggests that the stress drop is greatest for thrust events, least for normal events, and intermediate for strikeslip events (e.g., McGarr and Fletcher, 2002; Allmann and Shearer, 2009; Hardebeck and Aron, 2009). By contrast, the values of the median stress drops are $0.146 \pm 0.004$, $0.150 \pm 0.008$, and $0.165 \pm 0.010 \mathrm{MPa}$ for thrust, normal, and strike-slip events, respectively (Fig. 6a). The median stress of strike-slip events is significantly larger than that of thrust events, which is consistent with the latest global observation (Allmann and Shearer, 2009).

We further repeat the calculations of the median stress drop within three magnitude bins $\left(4 \leq M_{\mathrm{w}}<5,5 \leq M_{\mathrm{w}}\right.$ $<6$, and $6 \leq M_{\mathrm{w}} \leq 7.6$; Fig. 6) and in different source-depth 


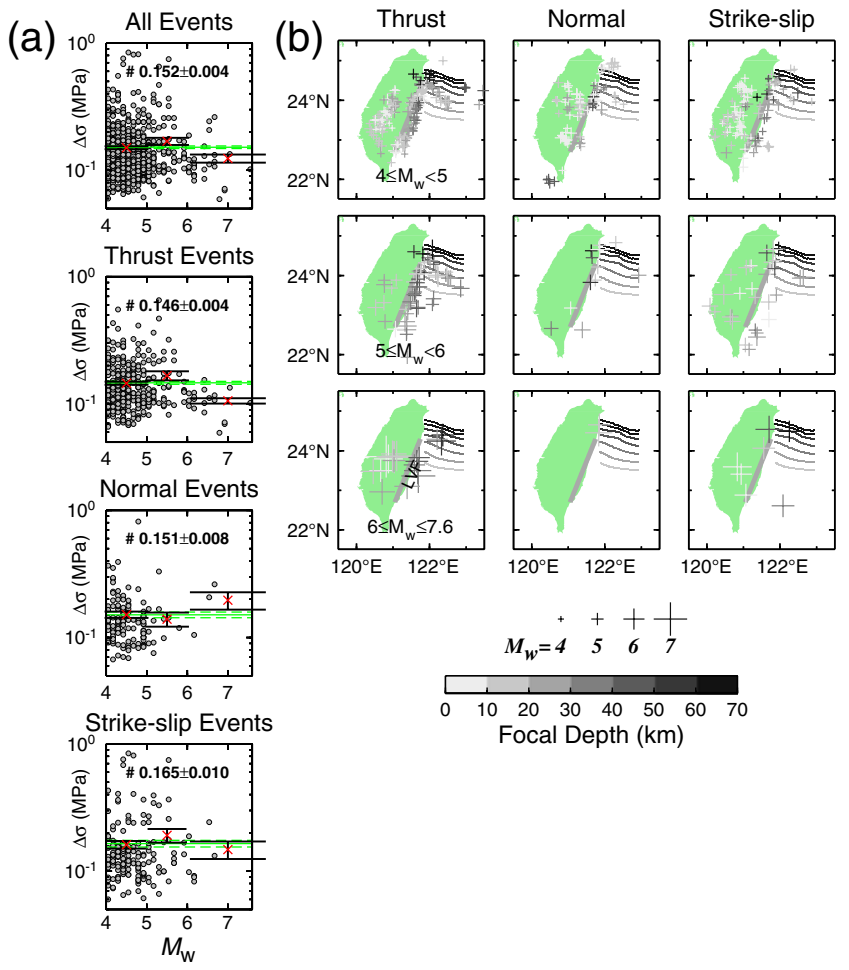

Figure 6. (a) Variations of stress drop with magnitude for all events as well as for thrust, normal, and strike-slip events. Estimated stress drop, circles. Solid lines represent the best-fitting lines, and the dashed lines indicate the $68 \%$ confidence limits in our regression. Crosses denote the median stress drop within each magnitude bin, and the associated bars indicate the $68 \%$ confidence limits. The numbers in each diagram present the best regression results. (b) Spatial distribution of the events used in each magnitude bin for different faulting types. Epicenters, crosses. Lines of varying gray scale represent the depth contours of the upper boundaries of the subducting slab (Wu et al., 2009). The color version of this figure is available only in the electronic edition.

intervals (Fig. 7). We consider changes in the values of the median stress drop significant if (1) sufficient number of events $(\geq 10)$ are available to compute the median value, and (2) they deviate from the median values derived from all events for the respective moment magnitude bin and depth interval by more than one standard deviation. We find no dependence of the median stress drop on moment magnitude for normal and strike-slip events, whereas the median stress drop significantly decreases from $0.145( \pm 0.004) \mathrm{MPa}$ for small thrust events $\left(4 \leq M_{\mathrm{w}} \leq 5\right)$ to $0.106( \pm 0.005) \mathrm{MPa}$ for large thrust events $\left(6 \leq M_{\mathrm{w}} \leq 7.6\right.$; Fig. 6a). This variation pattern is consistent with the observation of Allmann and Shearer (2009). We also draw the same conclusion if we lump all types of focal mechanisms together (Fig. 6a). We have examined the spatial distribution of large thrust earthquakes but found no specific pattern for a dependence of the median stress drop on the locations of the epicenters (Fig. 6b).

In examining the change of the stress drop with depth, Allmann and Shearer (2009) found a slight increase in the median stress drop at 35-40-km depth, which may be asso-
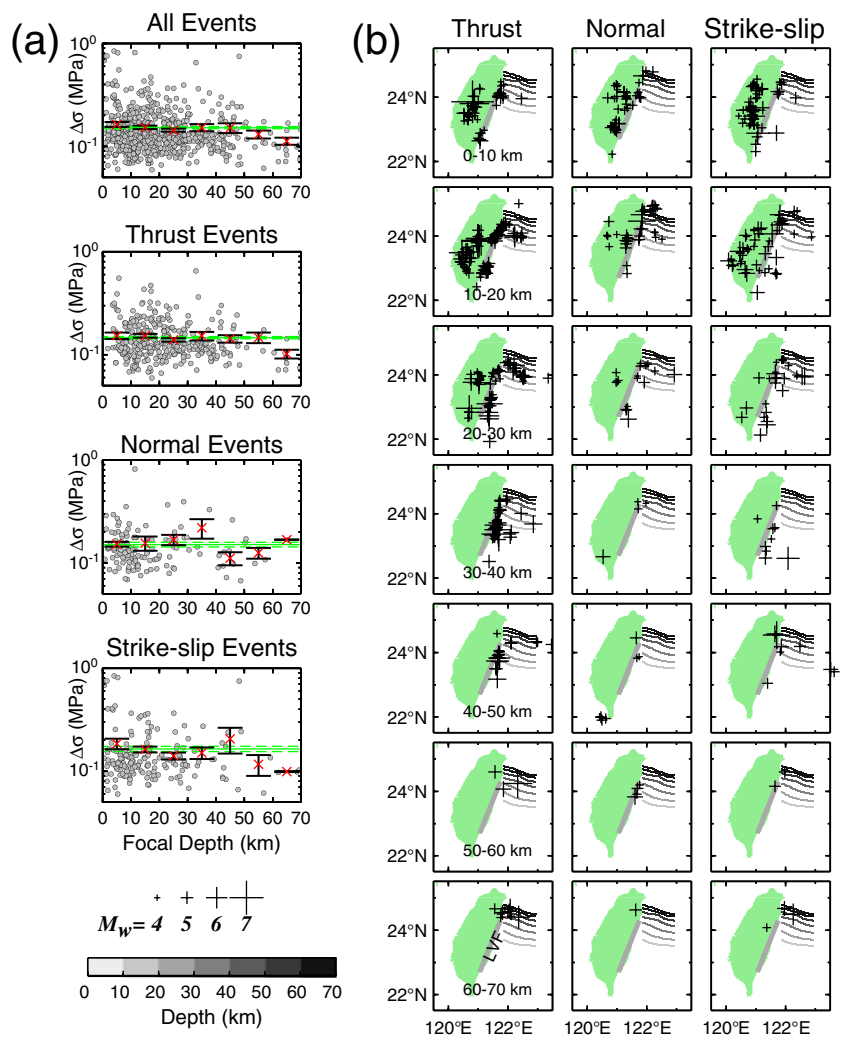

Figure 7. (a) Variations of stress drop with depth for all events as well as for thrust, normal, and strike-slip events. Solid lines represent the best-fitting lines and the dashed lines indicate the $68 \%$ confidence limits in our regression. Crosses denote the median stress drop within each depth interval, and the associated bars indicate the $68 \%$ confidence limit. (b) Spatial distribution of the events used in each depth interval for different faulting types. Epicenters, crosses. Lines of varying gray scale represent the depth contours of the upper boundaries of the subducting slab (Wu et al., 2009). The color version of this figure is available only in the electronic edition.

ciated with an increase in shear-wave velocity at the Moho. The stress drop derived from earthquake spectra, however, can be very sensitive to the chosen velocity model (Allmann and Shearer, 2007). Therefore, the increase in the stress drop may not be truly related to the Moho. In our observation, we find a significant decrease in the stress drop at $50-70-\mathrm{km}$ depth regardless of faulting types (Fig. 7a). Moreover, taking different faulting types into account, significant decreases in the median stress drops are observed at 60-70-, 40-50-, and 20-30-km depth for thrust, normal, and strike-slip events, respectively (Fig. 7a). This seems to indicate a weak zone where the events with relatively small median stress drop are distributed along the Ryukyu subduction interface and the Longitudinal Valley fault (e.g., Allmann and Shearer, 2009; Fig. 7b).

\section{Robustness of Empirical Relations}

One of our intentions in this exercise has been simply to examine whether the estimation of earthquake focal zone 
geometrical parameters is applicable for smaller events by comparing it with the global study of Kagan (2002). It is essential to analyze all events in a self-consistent manner to minimize the biases inherent in different methods when comparing the scaling characteristics. We, thus, choose to use the same processing parameters: one-day aftershocks, the magnitude-dependent relation in equation (2), shallow events (depth $\leq 70 \mathrm{~km}$ ), and $2 \sigma$ confidence area, in a manner consistent with Kagan (2002). Because no deterministic method exists in the aftershock selection (Kagan, 2002), however, here we test our results by repeating the same procedure with respect to four critical parameters: the maximum distance for the aftershock selection, time span for aftershock sequence selection, the depth limit for the mainshock selection, and the level of aftershock confidence area.

\section{Maximum Distance for Aftershock Selection}

A different magnitude-distance criterion to aftershock selection will lead to different aftershock zone size. We test this by adopting a widely used empirical magnitude-distance relation of Kasahara (1981) (e.g., Chen and Wu, 2006)

$$
R_{\mathrm{m}}=10^{\left(0.5 M_{\mathrm{w}}-1.8\right)} \mathrm{km} .
$$

This magnitude-distance criterion selects a relatively small number of events to represent aftershock zone size, but we found no statistical difference between the results derived from equations (2) and (23) (E) Fig. S1, available in the electronic supplement).

\section{Time Span for Aftershock Sequence Selection}

As pointed out by previous studies (Tajima and Kanamori, 1985a; Henry and Das, 2001), the aftershock zone may expand with time. Following previous practices (Henry and Das, 2001; Kagan, 2002), we determine the aftershock zone dimensions by using 7-day and 30-day aftershocks. In contrast to the result of Henry and Das (2001), no significant aftershock zone expansion is observed from our catalog (E) Fig. S2, available in the supplement). We, thus, choose to use 1-day aftershocks to approximate aftershock zone dimensions, as in Kagan (2002).

\section{Focal Depths of Mainshocks}

In our data set, the focal depths of mainshocks range from 0 to $70 \mathrm{~km}$. The distribution of earthquakes shows that the relatively shallow events $(\leq 35-\mathrm{km}$ depth) are fairly evenly distributed in the crust and shallow subduction zone with various focal mechanisms, whereas the relatively deep events (>35-km depth) are expected to stem predominantly from the subduction zone, especially for the thrust events (e.g., Kao et al., 1998, 2000; Kao and Jian, 2001; Fig. 1). Different depth selection implies different tectonic environments. We examine the effect of the focal depth selection for the mainshocks on the regression results by deriving the empirical relationships for the relatively shallow, deep, and all events, respectively. Our results show that no significant difference exists among the relationships derived from different depth ranges (E) Fig. S3, available in the supplement). On the basis of these experiments, we conclude that the effects of the maximum distance for the aftershock selection, time span for aftershock sequence selection, and the depth limit for the mainshock selection on the regression results are minor.

\section{Level of Aftershock Confidence Area}

As described in the section of parameters of aftershock zone dimensions (equations 9 and 10), the level of aftershock confidence zone critically affects the estimation of aftershock zone dimensions. As expected, a more restrictive value of the confidence level would reduce the aftershock zone size. Because the aftershock zone dimensions may be overestimated by using the $2 \sigma$ confidence area (Fig. 3), here we use the $1 \sigma$ confidence area to calculate the aftershock zone dimensions. Overall, the results show a systematical reduction in the aftershock zone dimensions and an increase of about one order of magnitude in the stress drop (E) Figs. S4, S5, and S6, available in the supplement). In this case, the stress drop ranges from 0.47 to $6.75 \mathrm{MPa}$ with a median value of $1.21 \mathrm{MPa}$, which is consistent with the observation for crustal events in Japan (Oth et al., 2010). Even though using the $1 \sigma$ confidence area seems to yield a more reasonable distribution of the stress drop, this does not change our main conclusions.

\section{Conclusions}

We have conducted a comprehensive analysis of aftershock zone sizes for earthquakes in Taiwan to provide an independent examination of earthquake scaling behavior. For the first time, a set of regional empirical relationships between the aftershock zone dimensions (length, width, and area) and moment magnitude ranging from $M_{\mathrm{w}}=4.0$ to 7.6 have been established for the Taiwan region. The empirical relationships of aftershock zone dimensions obtained in this study remain valid over the entire magnitude range and are independent of faulting types. Moreover, the ratio $(w / l)$ is independent of faulting types and increases slightly with moment magnitude, indicating that aftershock zone width $(w)$ grows faster than the aftershock zone length $(l)$ with increasing moment magnitude.

The value of the exponent in the scaling relation between the aftershock zone length and seismic moment is $3.13 \pm 0.13$, supporting the power-law model in which scalar moment is proportional to the cube of rupture length. Moreover, together with the conclusion drawn by Kagan (2002), we suggest that earthquakes of both small $\left(M_{\mathrm{w}}=4.0\right)$ and large $\left(M_{\mathrm{w}} \geq 7.0\right)$ moment magnitudes have similar focal zone geometrical parameters. 
On the other hand, the values of aftershock zone width and area in our $W-M_{\mathrm{w}}$ and $A-M_{\mathrm{w}}$ relationships are significantly larger than those of Wells and Coppersmith (1994). Nevertheless, the slopes in the $W-M_{\mathrm{w}}$ and $A-M_{\mathrm{w}}$ relationships from our regressions have values similar to these of Wells and Coppersmith (1994). This indicates that aftershock zone dimensions determined by the two-dimensional Gaussian distribution of one-day aftershocks are proportional to the estimation of Wells and Coppersmith (1994), who selected aftershocks subjectively.

We have also provided an independent examination on the variations of the median stress drop by using the scaling relation between the moment magnitude and aftershock zone area. Our robust observations are that the median stress drop of strike-slip earthquakes $(0.165 \pm 0.010 \mathrm{MPa})$ is significantly larger than that of thrust events $(0.146 \pm$ $0.004 \mathrm{MPa}$ ), and the median stress drops of normal and strike-slip events are independent of moment magnitude but significantly decrease for large thrust events (from $0.145 \pm$ $0.004 \mathrm{MPa}$ for small thrust events of $4 \leq M_{\mathrm{w}} \leq 5$ to $0.106 \pm$ $0.005 \mathrm{MPa}$ for large thrust events of $\left.6 \leq M_{\mathrm{w}} \leq 7.6\right)$. These variation patterns of the stress drop are in good agreement with the latest global observation of Allmann and Shearer (2009). Moreover, regardless of faulting types, the median stress drop decreases for larger $\left(6 \leq M_{\mathrm{w}} \leq 7.6\right)$ and relatively deep (depth $\sim 60-70 \mathrm{~km}$ ) events. Because the state of stress and the depth-dependent fault friction law in the Taiwan region are complex and uncertain, however, a solid explanation for the dependence of the stress drop on depth and faulting types is still elusive.

The estimation of the stress drop through the relation of moment magnitude and faulting area may be applicable to routine studies of earthquake stress drop. The estimation of aftershock zone dimensions, however, could be affected by the aftershock location quality and the numbers of aftershocks. Therefore, to make the estimations of the aftershock zone dimensions and stress drop more reliable, we could use the coseismic displacement derived from global positioning system (GPS) and/or strong motion data (e.g., Hu et al., 2007; Wu and $\mathrm{Wu}, 2007$ ) and the seismic moment of the event to obtain an estimation of the rupture area A through the relation $M_{0}=\mu u A$, where $\mu$ is the elastic shear modulus, and $u$ is the coseismic displacement (Kanamori and Anderson, 1975). Based on the estimated rupture area, we could calibrate the aftershock zone dimensions and achieve a better constraint on source scaling and the estimation of the stress drop. We could also apply this approach to earthquakes in California and Japan, where the seismogenic zones are better understood, the aftershocks zones are well constrained, and the stress drops have been estimated for main events and aftershocks (e.g., Nazareth and Hauksson, 2004; Felzer and Brodsky, 2006; Hardebeck and Aron, 2009; Oth et al., 2010; Omuralieva et al., 2012). It will provide an additional calibration for our approach by comparing the outcomes from earthquakes in different tectonic environments.

\section{Data and Resources}

The earthquake catalog used in this study was provided by the Central Weather Bureau, the government meteorological research and forecasting institute of Taiwan. All figures were made by the Generic Mapping Tools (GMT) software (Wessel and Smith, 1998).

\section{Acknowledgments}

The authors wish to thank Ia Shengelia and an anonymous reviewer for their thoughtful comments, which helped improve the manuscript. This work was supported by the Academia Sinica in Taiwan. L. Z. is supported by the National Science Council of Taiwan under Grant NSC100-2116-M-001-022.

\section{References}

Allmann, B. P., and P. M. Shearer (2007). Spatial and temporal stress drop variations in small earthquakes near Parkfield, California, J. Geophys. Res. 112, B04305, 17 pp., doi: 10.1029/2006JB004395

Allmann, B. P., and P. M. Shearer (2009). Global variations of stress drop for moderate to large earthquakes, J. Geophys. Res. 114, B01310, 22 pp., doi: 10.1029/2008JB005821.

Anderson, E. M. (1951). The Dynamics of Faulting, Second Ed., Oliver and Boyd, Edinburgh, 206 pp.

Angelier, J. (1990). Geodynamic evolution of the eastern Eurasian margin, Tectonophysics 183, 362.

Bath, M. (1965). Lateral inhomogeneities in the upper mantle, Tectonophysics 2, 483-514.

Beresnev, I. (2003). Uncertainties in finite-fault slip inversions: to what extent to believe? (A critical review), Bull. Seismol. Soc. Am. 93, 2445-2458.

Blaser, L., F. Krüger, M. Ohrnberger, and F. Scherbaum (2010). Scaling relations of earthquake source parameter estimates with special focus on subduction environment, Bull. Seismol. Soc. Am. 100, 2914-2926.

Bonilla, M. G., R. K. Mark, and J. J. Lienkaemper (1984). Statistical relations among earthquake magnitude, surface rupture length and surface fault displacement, Bull. Seismol. Soc. Am. 74, 2379-2411.

Chen, C.-C., and Y.-X. Wu (2006). An improved region-time-length algorithm applied to the 1999 Chi-Chi, Taiwan, earthquake, Geophys. J. Int. 166, 1144-1147.

Chen, R.-Y., H. Kao, W.-T. Liang, T.-C. Shin, Y.-B. Tsai, and B.-S. Huang (2009). Three-dimensional patterns of seismic deformation in the Taiwan region with special implication from the 1999 Chi-Chi earthquake sequence, Tectonophysics 466, 140-151.

Chi, W.-C., and D. Dreger (2002). Finite Fault Inversion of the September $25,1999,\left(M_{\mathrm{w}}=6.4\right)$ Taiwan earthquake: implications for GPS displacements of Chi-Chi, Taiwan Earthquake sequence, Geophys. Res. Lett. 29, 1694,4 pp., doi: 10.1029/2002GL015237.

Chi, W.-C., and D. Dreger (2004). Crustal deformation in Taiwan: results from finite source inversions of six $M_{\mathrm{w}}>5.8$ Chi-Chi aftershocks, J. Geophys. Res. 109, B07305, 16 pp., doi: 10.1029/2003JB002606.

Dowrick, D. J., and D. A. Rhoades (2004). Relations between earthquake magnitude and fault rupture dimensions: How regionally variable are they? Bull Seismol. Soc. Am. 94, 776-788.

Felzer, K. R., and E. E. Brodsky (2006). Decay of aftershock density with distance indicates triggering by dynamic stress, Nature 441, 735-738.

Hanks, T. C., and W. H. Bakun (2002). A bilinear source-scaling model for M- $\log$ A observations of continental earthquakes, Bull. Seismol. Soc. Am. 92, 1841-1846.

Hanks, T. C., and W. H. Bakun (2008). M-logA observations for recent large earthquakes, Bull. Seismol. Soc. Am. 98, 490-494.

Hanks, T. C., and H. Kanamori (1979). A moment magnitude scale, J. Geophys. Res. 84, 2348-2350.

Hardebeck, J. L., and A. Aron (2009). Earthquake stress drops and inferred fault strength on the Hayward fault, east San Francisco Bay, California, Bull. Seismol. Soc. Am. 99, 1801-1814. 
Henry, C., and S. Das (2001). Aftershock zones of large shallow earthquakes: Fault dimensions, aftershock area expansion, and scaling relations, Geophys. J. Int. 147, 272-293.

Hsu, S.-K., and B. Deffontaines (2009). An introduction to geodynamics and active tectonics in East Asia, Tectonophysics 466, 135-139.

Hu, J.-C., L.-W. Cheng, H.-Y. Chen, Y.-M. Wu, J.-C. Lee, Y.-G. Chen, K.-C. Lin, R.-J. Rau, H. Kuochen, H.-H. Chen, S.-B. Yu, and J. Angelier (2007). Coseismic deformation revealed by inversion of strong motion and GPS data: The 2003 Chengkung earthquake in eastern Taiwan, Geophys. J. Int. 169, 667-674.

Huang, M.-W., J.-H. Wang, R.-D. Hwang, and K.-C. Chen (2002). Estimates of source parameters of two large aftershocks of the 1999 Chi-Chi, Taiwan, earthquake in the Chia-Yi area, Terr. Atmos. Ocean. Sci. 13, 299-312.

Kagan, Y. Y. (2002). Aftershock zone scaling, Bull. Seismol. Soc. Am. 92, 641-655.

Kanamori, H., and D. L. Anderson (1975). Theoretical basis of some empirical relations in seismology, Bull. Seismol. Soc. Am. 65, 1073-1095.

Kao, H., and P.-R. Jian (2001). Seismogenic patterns in the Taiwan region: insights from source parameter inversion of BATS data, Tectonophysics 333, 179-198.

Kao, H., G.-C. Huang, and C.-S. Liu (2000). Transition from oblique subduction to collision in the northern Luzon arc-Taiwan region: Constraints from bathymetry and seismic observations, J. Geophys. Res. 105, 3059-3080.

Kao, H., S.-S. J. Shen, and K.-F. Ma (1998). Transition from oblique subduction to collision: Earthquakes in the southernmost Ryukyu arcTaiwan region, J. Geophys. Res. 103, 7211-7229.

Kasahara, K. (1981). Earthquake Mechanics, Cambridge University Press, Cambridge, England, 248 pp.

Konstantinou, K. I., G. A. Papadopoulos, A. Fokaefs, and K. Orphanogiannaki (2005). Empirical relationships between aftershock area dimensions and magnitude for earthquakes in the Mediterranean Sea region, Tectonophysics 403, 95-115.

Leonard, M. (2010). Earthquake fault scaling: Self-consistent relating of rupture length, width, average displacement, and moment release, Bull. Seismol. Soc. Am. 100, 1971-1988.

Mai, P. M., and G. C. Beroza (2000). Source scaling properties from finite fault-rupture models, Bull. Seismol. Soc. Am. 90, 604-615.

Manighetti, I., M. Campillo, S. Bouley, and F. Cotton (2007). Earthquake scaling, fault segmentation, and structural maturity, Earth Planet. Sci. Lett. 253, 429-438.

Mayeda, K., and W. R. Walter (1996). Moment, energy, stress drop, and source spectra of western United States earthquakes from regional coda envelopes, J. Geophys. Res. 101, 11,195-11,208.

Mayeda, K., L. Malagnini, and W. R. Walter (2007). A new spectral ratio method using narrow band coda envelopes: Evidence for non-selfsimilarity in the Hector Mine sequence, Geophys. Res. Lett. 34, L11303, 5 pp., doi: 10.1029/2007GL030041.

McGarr, A., and J. B. Fletcher (2002). Mapping apparent stress and energy radiation over fault zones of major earthquakes, Bull. Seismol. Soc. Am. 92, 1633-1646.

Murotani, S., H. Miyake, and K. Koketsu (2008). Scaling of characterized slip models for plate-boundary earthquakes, Earth Planets Space 60, 987-991.

Nazareth, J. J., and E. Hauksson (2004). The seismogenic thickness of the southern California crust, Bull. Seismol. Soc. Am. 94, 940-960, doi: 10.1785/0120020129.

Omuralieva, A. M., A. Hasegawa, T. Matsuzawa, J. Nakajima, and T. Okada (2012). Lateral variation of the cutoff depth of shallow earthquakes beneath the Japan Islands and its implications for seismogenesis, Tectonophysics 518, 93-105.

Oth, A., D. Bindi, S. Parolai, and D. D. Giacomo (2010). Earthquake scaling characteristics and the scale-(in)dependence of seismic energy-tomoment ratio: Insights from KiK-net data in Japan, Geophys. Res. Lett. 37, L19304, 5 pp., doi: 10.1029/2010GL044572.

Pegler, G., and S. Das (1996). Analysis of the relationship between seismic moment and fault length for large crustal strike-slip earthquakes between 1977-72, Geophys. Res. Lett. 23, 905-908.
Press, W., S. A. Teukolsky, V. T. Vetterling, and B. P. Flannery (1992). Numerical Recipes in Fortran 77: The Art of Scientic Computing, Second Ed., Cambridge University Press, Cambridge.

Prieto, G., P. M. Shearer, F. L. Vernon, and D. Kilb (2004). Earthquake source scaling and self-similarity estimation from stacking $P$ and $S$ spectra, J. Geophys. Res. 109, B08310, 13 pp., doi: 10.1029/ 2004JB003084.

Romanowicz, B. (1992). Strike-slip earthquakes on quasi-vertical transcurrent faults: Inferences for general scaling relations, Geophys. Res. Lett. 19, 481-484.

Romanowicz, B. (1994). Comment on "A reappraisal of large earthquake scaling by C. H. Scholz", Bull. Seismol. Soc. Am. 84, 1675-1676.

Romanowicz, B., and L. J. Ruff (2002). On moment-length scaling of large strike slip earthquakes and the strength of faults, Geophys. Res. Lett. 29, 1604.

Scholz, C. H. (1982). Scaling laws for large earthquakes: Consequences for physical models, Bull. Seismol. Soc. Am. 72, 1-14.

Scholz, C. H. (1994a). A reappraisal of large earthquake scaling, Bull. Seismol. Soc. Am. 84, 215-218.

Scholz, C. H. (1994b). Reply to "Comment on "A reappraisal of large earthquake scaling by C. Scholz' by Barbara Romanowicz”, Bull. Seismol. Soc. Am. 84, 1677-1678.

Scholz, C., C. Aviles, and S. Wesnousky (1986). Scaling differences between large interplate and intraplate earthquakes, Bull. Seismol. Soc. Am. 76, 65-70.

Shaw, B. E. (2009). Constant stress drop from small to great earthquakes in magnitude-area scaling, Bull. Seismol. Soc. Am. 99, 871-875.

Sibuet, J.-C., B. Deffontaines, S.-K. Hsu, N. Thareau, J. P. Le Formal, C.-S. Liu, and A. Party (1998). Okinawa trough backarc basin: Early tectonic and magmatic evolution, J. Geophys. Res. 103, 30,245-30,267.

Somerville, P., K. Irikura, R. Graves, S. Sawada, D. Wald, N. Abrahamson, Y. Iwasaki, T. Kagawa, N. Smith, and A. Kowada (1999). Characterizing crustal earthquake slip models for the prediction of strong ground motion, Seismol. Res. Lett. 70, 59-80.

Stock, C., and E. G. C. Smith (2000). Evidence for different scaling of earthquake source parameters for large earthquakes depending on faulting mechanism, Geophys. J. Int. 143, 157-162.

Strasser, F. O., M. C. Arango, and J. J. Bommer (2010). Scaling of the source dimensions of interface and intraslab subduction-zone earthquakes with moment magnitude, Seismol. Res. Lett. 81, 941-950.

Tajima, F., and H. Kanamori (1985a). Aftershock area expansion and mechanical heterogeneity of fault zone within subduction zones, Geophys. Res. Lett. 12, 345-348.

Tajima, F., and H. Kanamori (1985b). Global survey of aftershock area expansion patterns, Phys. Earth Planet. In. 40, 77-134.

Tajima, F., and B. L. N. Kennett (2012). Interlocking of heterogeneous plate coupling and aftershock area expansion pattern for the 2011 TohokuOki $M_{\mathrm{w}} 9$ earthquake, Geophys. Res. Lett. 39, L05307, 5 pp., doi: 10.1029/2011GL050703.

Vakov, A. V. (1996). Relationships between earthquake magnitude, source geometry and slip, mechanism, Tectonophysics 261, 97-113.

Wang, J.-H., and S.-S. Ou (1998). On scaling of earthquake faults, Bull. Seismol. Soc. Am. 88, 758-799.

Wells, D. L., and K. J. Coppersmith (1994). New empirical relationships among magnitude, rupture length, rupture width, rupture area, and surface displacement, Bull. Seismol. Soc. Am. 84, 974-1002.

Wessel, P., and W. M. F. Smith (1998). New improved version of generic mapping tools released, EOS Trans. AGU 79, 579.

Woessner, J., and S. Wiemer (2005). Assessing the quality of earthquake catalogues: Estimating the magnitude of completeness and Its uncertainty, Bull. Seismol. Soc. Am. 95, 684-698.

Wu, Y.-M., and C.-F. Wu (2007). Approximate recovery of coseismic deformation from Taiwan strong-motion records, J. Seismol. 11, 159-170.

Wu, Y.-M., C.-H. Chang, N. C. Hsiao, and F. T. Wu (2003). Relocation of the 1998 Rueyli, Taiwan, earthquake sequence using three-dimensions velocity structure with stations corrections, Terr. Atmos. Ocean. Sci. 14, 421-430. 
Wu, Y.-M., C.-H. Chang, L. Zhao, J. B. H. Shyu, Y.-G. Chen, K. Sieh, and J. P. Avouac (2007). Seismic tomography of Taiwan: Improved constraints from a dense network of strong-motion stations, J. Geophys. Res. 112, no. B08312, 13, doi: 10.1029/2007JB004983.

Wu, Y.-M., Y.-J. Hsu, C.-H. Chang, L. S. Teng, and M. Nakamura (2010). Temporal and spatial variation of stress field in Taiwan from 1991 to 2007: Insights from comprehensive first motion focal mechanism catalog, Earth Planet. Sci. Lett. 298, 306-316.

Wu, Y.-M., J. B. H. Shyu, C.-H. Chang, L. Zhao, M. Nakamura, and S.-K. Hsu (2009). Improved seismic tomography offshore northeastern Taiwan: Implications for subduction and collision processes between Taiwan and the southernmost Ryukyu, Geophys. J. Int. 178, 1042-1054.

Wu, Y.-M., L. Zhao, C.-H. Chang, and Y.-J. Hsu (2008). Focal mechanism determination in Taiwan by genetic algorithm, Bull. Seismol. Soc. Am. 98, 651-661.

Yen, Y.-T., and K.-F. Ma (2011). Source-scaling relationship for $M$ 4.6-8.9 earthquakes, specifically for earthquakes in the collision zone of Taiwan, Bull. Seismol. Soc. Am. 101, 464-481.
Zahradník, J., and F. Gallovič (2010). Toward understanding slip inversion uncertainty and artifacts, J. Geophys. Res. 115, B09310, 16 pp., doi: 10.1029/2010JB007414.

Institute of Earth Sciences

Academia Sinica, 128, Sec. 2

Academia Road, Nangang

Taipei 11529, Taiwan

zhaol@earth.sinica.edu.tw

(W.-N.W., L.Z.)

Department of Geosciences

National Taiwan University

No. 1, Sec. 4, Roosevelt Road

Taipei 10617, Taiwan

(Y.-M.W.)

Manuscript received 15 May 2012 